\title{
A Less Perfect But Freer Society?
}

\author{
Gary T Marx*
}

Les utopies sont réalisables. La vie marche vers les utopies. Et peut-être un siècle nouveau commence-t-il, un siècle où les intellectuels et la classe cultivée rêveront aux moyens d'éviter les utopies et de retourner à une société non utopique moins 'parfaite' et plus libre.**

Nicholas Bertiadeff

The first edition of Huxley's Brave New World began with the above quotation from religious scholar and former Marxist Nicholas Bertiadeff. We continually hear about what the newest technology will give to us. Less frequently do we hear about what we will give to it or what it will uninvitedly do to us. We must attend not only to the truth claims of the advocates, but ask about the costs to the individual and society. Bravo to these young scholars for contributing to the recognition of this.

It most decidedly is not, as so much techno-propaganda suggests, a win/win situation with only rainbows and happy endings, but neither is it only a sugar-coated Faustian mirage. Seeing clearly what it is can lead to political choices that move toward the former, or at least that do not permit drifting ever closer to the latter. Every ray of light has a shadow, and mirages mix with the literal world. At its best, a caring, but open, scholarly skepticism can reflect reality and the need to avoid the seduction of misleading truths and the exaggerated promises of contemporary technophiles and assorted camp followers. The Greek etymology of utopia is an imaginary place ('ou' = no, 'topos' $=$ no place!).

These young scholars are off to a fine start and who better to write about the future than those who will experience it for such a large proportion of their lives? As one who has been concerned with these issues for more than 50 years ${ }^{1}$ as a citizen from agents provocateurs in the civil rights movement in Berkeley, to a bugged hotel room in the Hotel Metropol ${ }^{2}$ in Moscow, and as a scholar writing about civil rights, undercover

DOI: $10.21552 / \mathrm{edpl} / 2018 / 4 / 4$

* Gary T Marx, Professor Emeritus MIT, has been reflecting on freer, but less than perfect, societies for more than five decades since receiving his PhD from the University of California, Berkeley. This and related topics are explored in publications such as Protest and Prejudice; Muckraking Sociology; Undercover: Police Surveillance in America; Undercover: Police Surveillance in Comparative Perspective (with C Fijnaut) and Windows into the Soul Surveillance and Society in an Age of High Technology. For correspondence: $<$ gtmarx@mit.edu>,www.garymarx.net.

** English translation: 'Utopias are believed to be reachable. Life points towards them. Perhaps one day intellectuals and thoughtful persons will find ways to avoid utopias and return to a non-utopian, less "perfect" but freer society'.

1 Gary T Marx, 'What's It All About? Reflections on Meaning in a Career' in R Darling and P Stein, Sociological Lives (Temple Univ Press 2016) and reflections under 'Section 7 Academic Career and Some Social Research Issues' <http://web.mit.edu/gtmarx/www/garyhome.html> accessed 3 December 2018.

2 Built in 1906, the Bolshevik's nationalised it in 1918 and it housed living and work quarters of the Soviet bureaucracy. In the 1930 s it was converted to its initial hotel function with some upgrading of eavesdropping capabilities. 
police and surveillance, it is good indeed to see so much current academic and policy attention to privacy and related issues and to see the leading role played by the European Community in offering principles, legislation and policies.

Consistent with the volume's theme I will briefly refer to some developments baring on the future which I hope they and others will pursue with energy, clarity and wisdom, avoiding the shoals of utopianism, as well as dystopianism. ${ }^{3}$ Discussions of the future require humility. Regarding specific predictions, social scientists who failed to predict the civil rights movement, the coming of computerisation, the end of the cold war, 9/11 and subsequent events in a jarring context of globalisation and global warming may do no better than telling time from a broken clock which will sometimes (twice a day) be correct. But what is life without risk?

Certainly the colonisation of our lives and the continued emphasis on mechanical prevention and risk avoidance will continue to accelerate. We will likely see brain, body and machine mergings and a vast increase in the use of unseen and unknown artificial intelligence algorithms based on mega data bases from sensors embedded everywhere and in everything, With this we will also see the galloping, rather than the trotting of the ability to engineer what Boete several centuries ago called voluntary servitude and by now has become mandatory voluntarism. ${ }^{4}$ This is ever more seen as the default, low, or invisible socialisation/propaganda/discipline and the conditions of contemporary life give us almost no choice but to go along, often not even offering any awareness that we are.

For futures (really 'nows' or 'soon in a neighbourhood near you'), there are of course the exotic, ghee whiz, newsworthy devices such as drones that look like flies and hover like hummingbirds, 'snakebots' that can slither under doors, and smart dust, micro motes and cyborg beetles (live insects) that can portage cameras and other sensors. ${ }^{5}$ There will be ever more sensors from the environment and what is unique to a person (DNA, smell, voice, face, gait and behaviour patterns including social media) taken individually, or more often combined, that are presumed to be linked to identification then tied to risk or opportunity predictors and access or denial. We are seeing the expansion of the new biometrics (the ultimate windows into the soul) including implants, brain scans and genetic analysis along with unimagined cyborg forms. Any shopping list as well must also include robots and the internet of things (IOT) and, running through much of the above, artificial intelligence and cybersecurity.

3 This summarises some of the themes in a recent discussion with Spanish sociologist Francisco Morente on thinking and writing about privacy and surveillance issues as part of a broader interest in democratic social orders. ('I break in Order to Reveal' Fran Morente Interview with Gary T Marx about Windows into the Soul: Surveillance and Society in an Age of High Technology (forthcoming) <https://www .press.uchicago.edu/ucp/books/book/chicago/W/bo22228665.html> accessed 3 December 2018).

4 E Boétie, The Politics of Obedience: The Discourse of Voluntary Servitude (Black Rose Books 1997). Marx, Windows into the Soul, ibid. On our ever more vulnerable infra-structures, including the multiple, unseen and unknown supply chains see Bruce Schneier, Click Here to Kill Everybody: Security and Survival in a Hyperconnected World (Norton and Co 2018). On the self-driving car: Samuel Gibbs, 'Uber's SelfDriving Car Saw the Pedestrian but Didn't Swerve - Report.' The Guardian (8 May 2018) <https://www.theguardian.com/technology/2018/may/ 08/ubers-self-driving-car-saw-the-pedestrian-but-didnt-swerve-report> accessed 5 December 2018. 
The issues however go far beyond protecting passive personal records in a database. For what is a person profited, if he or she shall gain full privacy, but lose understanding and autonomy and a safe environment (eg, lack of control over a self-driving car or an airplane that crashes or a medical device that automatically dispenses a deadly overdose, let alone facing cyber-attacks on communications, electrical, water, and transportation systems)? As inscrutable, unseen and relatively insecure networks grow ever larger and more connected, and as software called 'smart' and 'intelligent' continually learn from environments and go beyond recommending action, to taking action independently of humans, the ideal informed, consenting and reviewing subjects with access to their records as envisioned in the recent European General Data Protection Regulation have a lot to worry about. Among concerns must be the chasms and blind spots between nice words on paper and their application in complex, hazy, political environments treated in a recent volume by Bayamlioglu et al, forthcoming. ${ }^{6}$

A broad issue at a more philosophical level involves technical developments as perpetual dissatisfaction machines. Their promise of 'ever more and better' continually raises expectations and can bring new anxieties and insecurities. Playwright Neil Simon observed, 'nothing recedes like success'. That could be a warning that it doesn't last, but it could also mean that there is always another, even higher, mountain to climb: more security, more efficiency, more ease etc. Considering just security, note how contemporary fear has moved from an understood, known, visible, alien 'other' beyond the walls of the village or the fortified castle or home, to a less visible 'other' within the community or capable of remotely entering it. Walls are not what they used to be. With continuous bio-feedback and health monitoring, we become aware that the enemy might even reside within our own bodies. With modern culture, humans seem sentenced to a never sated quest in which 'progress' bootlegs in irony, dissatisfaction and new vulnerabilities. As Virilio observed with the invention of the ship we see the invention of the shipweck. ${ }^{7}$

In spite of all the bad news, social critics and academics secure within the nested environments of a university or research unit should not be too quick to fully abandon a qualified idea of progress as expressed by our Enlightenment and Renaissance progenitors. Independent scholars ought to come as neither a torchbearers for the Luddites, nor as beacons for the entrepreneurs. The relentless march of the omnipresent and totalizing mediation of information technologies onto, and into, our daily lives, is like air, everywhere. Without air we die, yet with too much we die as well. The technology is something of a two way street, even as structures and cultures of inequality push to make it one-way, or at least an expensive toll road. Certainly, there are tidal waves of momentum driving the depth and speed of current change and ever-greater penetration of supportive macro infrastructures. Yet the tidal waves come into existing

6 E Bayamlioglu et al (eds), BEING PROFILED: COGITAS ERGO SUM, 10 Years of Profiling the European Citizen (Amsterdam Univ Press 2018).

7 P Virilio, The Politics of the Worst. An interview with Philippe Petit (MIT Press 1999). 
complex, multi-layered environments, which will shape them, and have social consequences in ways not anticipated or even imagined.

It is clear why so many persons and organisations welcome the score cards the technology offers. If done with clear rules and valid data, it is easy to imagine cheerful robotic slaves bonded to Al programs. In the best self-help, individual responsibility traditions these can offer persons the chance to better themselves through continuous health monitoring, improved credit scores, careful measurement and rewards for work results, not to mention popularity and a rich social life through harvesting electronic friends and 'likes'. As well, when away, there is the bonus of the remote monitoring and control of homes and children and warnings about traffic congestion, driving while tired and hurricanes.

Yet, it is too easy to have a cheerleader response, just as it is too easy to have a fearful, abhorrent reflex response to technical developments. We face a complex set of shifting, and inherently debatable, trade-offs. In the case of the Internet for example, in spite of the increased use of mobile devices and the coming loT that can undercut locational and identity privacy, there are dissipating factors such as address anonymisers and encryption noted by Susan Landau ${ }^{8}$. The good news is that there are often choices. The bad news is that they can be costly and we need to be made aware of them.

As sociologist Egon Bittner pointed out, a screwdriver is a wonderful tool for projects, as well, it can be used to spread peanut butter on a sandwich or to stab someone. A market theory approach suggests that where there is a perceived need, suppliers will appear (whether legal or black market). The human spirit is creative and resilient and individuals and groups have resources to throw monkey wrenches into the system. There are always tacks in the shoes and ironic social arrangements. ${ }^{9}$ As James $\mathrm{M} \mathrm{Hard}$ ing documents there are also tools for cultural warfare and the weak (Brunton and Nissenbaum; Scott), as well as the stronger, have resources. ${ }^{10}$

In the face of the heavy determinisms of those who dismiss individual agency and transcendent cultural ideas regarding the dignity of the person as sideshows, attention to local contexts will show that sometimes the choices are between the good and the good (or the better), or at least between the bad and the worst (or in Machiavelli's words viewing 'the least bad as good'). Certainly the evaluation of such choices (or even the ability to see them) partly resides in the eyes of the beholder. Nonetheless, I disagree with writer Paul Goodman who once said that the lesser of two evils is not a choice between half a loaf and a whole one, but between more or less virulent forms of rat poison. Degrees matter. University Press 2016); F Brunton and H Nissenbaum, A User's Guide for Privacy and Protest (MIT Press 2013). 
The tide cannot be turned back, but it can be nudged and redirected a bit in cognisant and resilient environments. Yet choice initially requires awareness. Of particular importance and a great challenge for privacy and surveillance decency is the numbing or hiding of the possibility of awareness (or if present, the joining of awareness with seduction of various kinds as in 'an offer that can't be refused').

When one is cognisant of what is occurring a reaction is possible, even if only to negate or withdraw, let alone to try to change a situation, although awareness can also lead to hopelessness and depression, or at least mostly tending one's garden with Voltaire's. David Lyon calls attention to Bauman's concept of adiaphorization in which ethical implications are divorced from an action. ${ }^{11}$ This generates a specious sense of neutrality and irresponsibility. This distancing of ethics from systems and tools can also apply to the distanced (both spatially and emotionally) technocrat who says, 'I don't make the rules, I am just doing my job' ala Stanley Milgram's work on obedience to authority. $^{12}$ This reflects an unreflective deferral to instrumentality as the preeminent value and the divorce of action from accountability.

The observations of Erich Fromm apply here:

The danger of the past was that men became slaves. The danger of the future is that men may become robots.... Men are increasingly automatons, who make machines which act like men and produce men who act like machines; there reason deteriorates while their intelligence rises, thus creating the dangerous situation of equipping man with the greatest material power without the wisdom to use it. ${ }^{13}$

In bringing greater awareness of what is happening and what can be done, articles such as those that follow can help mitigate the danger.

I began my recent book Windows Into the Soul: Surveillance and Society in an Age of High Technology with a quote from Kafka's 1919 cautionary story 'In the Penal Colony'. The story is about a new technology described as 'a remarkable piece of apparatus' —a highly acclaimed, state-of-the art machine invented by a corrections officer for punishing inmates. The story ends when the machine malfunctions and kills its operator-an enthusiastic advocate of the benefits and infallibility of the machine. The sky is not now falling, even if that offers only modest grounds for rejoicing, there are after all holes in the ozone layer.

\footnotetext{
11 Z Bauman and D Lyon, Liquid Surveillance (Polity Press 2013).

12 S Milgram, Obedience to Authority: An Experimental View (Barnes and Noble 1974).

13 E Fromm, Escape From Freedom (Rinehart and Winston 1955).
} 